\title{
ANALISIS KEBERADAAN PAKAN ORANGUTAN DAN INDEKS SHANNON- WIENER PADA AREA REBOISASI ASRI DI KAWASAN TAMAN NASIONAL GUNUNG PALUNG
}

\begin{abstract}
(Analyses of Orangutan Food Supply and Shannon-Wiener Index at ASRI Forest Restoration in
\end{abstract} Gunung Palung National Park)

\author{
Nurul Ihsan Fawzi ${ }^{\left.1,3^{*}\right)}$, Erina Safitri ${ }^{2}$, Juliansyah ${ }^{1)}$, Farah Diba ${ }^{2)}$ \\ ${ }^{1}$ Alam Sehat Lestari, Jln. Sungai Mengkuang, Sukadana, Kalimantan Barat, Indonesia 78852 \\ ${ }^{2}$ Fakultas Kehutanan, Universitas Tanjungpura, Pontianak, Kalimantan Barat, Indonesia 78121 \\ ${ }^{3}$ Tay Juhana Foundation, Jln. Rawa Bebek Utara No. 26, Penjaringan, Jakarta Utara, Indonesia 14440 \\ *e-mail: nurul.ihsan.f@mail.ugm.ac.id
}

\section{Abstract}

Gunung Palung National Park had lost $35 \%$ of its primary forests over the past 30 years. A forest restoration program is thus vital to restore the damaged forest ecosystems. This study aims to analyze the presence of orangutan food supply and Shannon-Wiener index at Alam Sehat Lestari (ASRI) restoration site in Gunung Palung National Park. The method applies a species data collection of orangutan food (in 91 sample plots) and calculation of Shannon-Wiener index (in six 2009's plots). The result depicted approximately 65 species from 25 families found in ASRI restoration site. Eighty percent of those species indicated orangutan food. In addition, the restoration site is believed to prevent the orangutan conflict with a human due to food availability in restoration areas for orangutans. Analysis of the Shannon-Wiener index $\left(H^{\prime}\right)$ demonstrated a value of $H^{\prime}=$ 2.789, which indicated that the reforestation forest was in stable condition. The effect of increasing biodiversity as characterized by orangutan nests at restoration sites escalates the presence of wildlife.

Keywords: Forest Restoration, Gunung Palung National Park, Orangutan

Abstrak

Taman Nasional (TN) Gunung Palung telah kehilangan 35\% hutan primer selama 30 tahun terakhir. Program reboisasi diperlukan untuk mengembalikan ekosistem hutan yang telah rusak. Tujuan penelitian ini adalah untuk menganalisis keberadaan pakan orangutan dan indeks Shannon-Wiener di area reboisasi yang dilakukan oleh Yayasan Alam Sehat Lestari (ASRI) di kawasan TN Gunung Palung. Metode yang digunakan adalah monitoring terhadap 91 plot untuk identifikasi pakan orangutan dan 6 plot penanaman tahun 2009 untuk perhitungan indeks Shanon-Wiener. Hasilnya terdapat 65 spesies dari 25 suku yang ditemukan di lokasi reboisasi ASRI. Sebanyak $85 \%$ dari spesies tersebut adalah pakan orangutan. Selain itu, keberadaan area reboisasi membantu mencegah konflik ini karena orangutan dapat mencari makanan di area reboisasi. Analisis indeks Shannon-Wiener $\left(H^{\prime}\right)$ didapatkan nilai $H^{\prime}=2,789$, yang menunjukkan hutan hasil reboisasi berada dalam kondisi menengah atau stabil. Efek peningkatan biodiversitas ditandai dengan sarang-sarang orangutan ditemukan di lokasi reboisasi dan keberadaan satwa liar telah meningkat.

Kata kunci: Gunung Palung, Orangutan, Restorasi hutan 


\section{PENDAHULUAN}

Deforestasi di Pulau Kalimantan menyebabkan 14,4 juta hektar hutan primer hilang dari tahun $1973-2015^{1}$. Jumlah tersebut berkontribusi atas hilangnya sepertiga hutan primer di Pulau Kalimantan. Konversi menjadi perkebunan kelapa sawit (Elaeis guineensis) adalah penyebab utama deforestasi yang terjadi selama rentang tahun tersebut ${ }^{2,3}$. Deforestasi dapat memicu hilangnya biodiversitas akibat hilangnya habitat ${ }^{4}$. Dampak jangka panjang adalah memicu terjadinya perubahan iklim, terutama iklim lokal yang ditandai perubahan pola hujan dan peningkatan suhu ${ }^{5,6}$. Emisi karbon yang dihasilkan dari deforestasi tercatat sebanyak 1 - 1,2 petagram (Pg) karbon per tahun ${ }^{7,8}$.

Taman Nasional (TN) Gunung Palung (1 ${ }^{\circ} 3^{\prime}-1^{\circ} 22^{\prime}$ LU, 109 $54^{\prime}$ $110^{\circ} 28^{\prime}$ BT) merupakan salah satu kawasan lindung yang mengalami deforestasi yang cukup besar, terutama akibat pembalakan liar dan kebakaran hutan 9. TN Gunung Palung telah kehilangan 35\% hutan primernya selama tahun 1989 - $2016^{10}$. Deforestasi yang terjadi dapat berakibat buruk pada hilangnya habitat dan biodiversitas ${ }^{11}$. Upaya mengurangi laju deforestasi dan kehilangan biodiversitas diperlukan untuk mengmbalikan ekosistem hutan yang telah rusak melalui reboisasi atau restorasi hutan ${ }^{12}$.

Terminologi reboisasi sama dengan restorasi hutan, dimana adalah upaya untuk mengembalikan fungsi hutan dengan penanaman kembali pada hutan yang rusak ${ }^{13}$. Reboisasi berguna tidak hanya untuk perbaikan ekosistem pohon di hutan, tetapi berfungsi sebagai habitat dan penyedia makanan bagi satwa liar. Reboisasi yang berhasil mampu mengembalikan komposisi dan struktur hutan ${ }^{14}$. Hal tersebut membutuhkan perencanaan, monitoring, dan keberlanjutan pendanaan ${ }^{15}$.

Monitoring keberadaan pakan orangutan di lokasi reboisasi adalah penting untuk proyeksi keberhasilan program di masa depan. Hal ini karena TN Gunung Palung merupakan habitat bagi 2.500 orangutan dan orangutan membutuhkan ketersediaan makanan ${ }^{16}$. Orangutan adalah frugivora yang keberlanjutan hidupnya tergantung dari ketersediaan buah di dalam hutan ${ }^{17}$. Status konservasi orangutan Kalimantan (Pongo pygmaeus (Linnaeus, 1760)) adalah terancam punah ${ }^{18}$. Jumlah populasi orangutan saat di Kalimantan tersisa \pm 55.000 orangutan, dari yang sebelumnya mencapai 200.000 pada tahun 1990-an ${ }^{19}$.

Yayasan Alam Sehat Lestari (ASRI) bermitra dengan organisasi internasional Health in Harmony telah menginisiasi program reboisasi di TN Gunung Palung sejak tahun 2009. Program reboisasi tersebut memiliki fase monitoring dan evaluasi, terutama untuk reboisasi yang berbasis konservasi orangutan. Monitoring keberhasilan program reboisasi menggunakan indeks ShannonWiener menjadi salah satu yang dapat dilakukan. Hasil monitoring adalah mampu menilai keberagaman vegetasi hasil reboisasi. Tujuan penelitian ini adalah untuk menganalisis keberadaan pakan orangutan dan indeks Shannon- 
Wiener di area reboisasi yang dilakukan oleh ASRI di kawasan TN Gunung Palung. Analisis ini berguna untuk identifikasi ketersediaan pakan orangutan dan biodiversitasnya di masa mendatang.

\section{METODE PENELITIAN}

\section{Lokasi Penelitian}

Lokasi reboisasi terletak di Desa Laman Satong Km. 20, Kecamatan Matan Hilir Utara, Kabupaten Ketapang (-1.3678729, 110.2242137, gambar 1). Reboisasi dimulai pada tahun 2009 dengan menanam \pm 14.000 bibit. Lokasi ini berada dalam Kawasan TN Gunung Palung yang rusak akibat pembalakan liar (illegal logging) oleh perusahaan kayu ${ }^{20}$. Keberadaan perusahaan kayu tersebut menyebabkan terjadinya perforasi hutan, deforestasi dan degradasi hutan yang meluas akibat ikut serta serta masyarakat dalam aktivitas pembalakan liar. Pembalakan liar tersebut mengakibatkan hutan yang rusak ditumbuhi oleh gulma paku resam (Pteredium aquilinum) dan alang-alang (Imperata cylindrica). Paku resam dan alang-alang mudah terbakar ketika musim panas yang panjang. Hal ini diperlukan faktor eksternal agar regenerasi hutan dapat terjadi.

Total area reboisasi yang dilakukan selama 2009 - 2017 adalah 30 hektar. Reboisasi dilakukan multitahun dengan tahun penanaman 2009, 2013, 2014, 2015, 2016, dan 2017. Perbedaan tahun penanaman di lokasi yang sama adalah akibat dari keterbatasan dukungan dana dari donor dan keberlanjutan restorasi hutan. Penanaman dilakukan setiap musim hujan terutama pada bulan
November - Desember. Jumlah spesies yang ditanam setiap tahun penanaman adalah $\sim 30$ spesies. Kerapatan tanaman yang digunakan adalah 3.100 bibit per hektar ${ }^{21}$. Pada tahun 2013, 18 hektar lahan reboisasi yang telah ditanam terbakar dan menyisakan 1 hektar penanaman tahun 2009.

\section{Data dan Analisis}

Pengumpulan data dilakukan dari tanggal 15 Agustus 2017 hingga 1 Agustus 2018. Pengumpulan data ini adalah bagian dari monitoring program reboisasi. Sebanyak 91 plot ukuran $20 \mathrm{x}$ 20-meter yang dipilih secara acak menjadi lokasi pengambilan data (monitoring). Terdapat plot percobaan Assitted Natural Regeneration (ANR) tahun 2014 yang tidak dilakukan monitoring. Data yang dikumpulkan adalah jenis tanaman, tinggi, diameter basal, DBH, dan kondisi kesehatan tanaman. Data dikumpulkan untuk tahun penanaman 2009, 2013, 2014, 2015, 2016 dan 2017. Pohon yang telah dicatat jenis dan parameter pertumbuhannya, diberi label penanda untuk keberlanjutan program monitoring.

Terdapat enam plot ukuran $20 \times 20-$ meter tahun penanaman 2009 yang diambil datanya terpisah dari 91 plot. Plot tersebut adalah L1, L2, L4, K3, K4 dan K5. Sehingga total plot sampel yang diambil adalah 97 plot. Pengukuran plot terpisah secara acak ini untuk mengukur indeks keanekaragaman ShannonWiener. Data yang dikumpulkan adalah seluruh pohon dengan $\mathrm{DBH} \geq 5 \mathrm{~cm}$.

Analisis data menggunakan metode statistik deskriptif. Data tentang jenisjenis tanaman yang berupa nama lokal 
dikelaskan sesuai suku dan nama ilmiah. Identifikasi jenis-jenis pakan orangutan dilakukan dengan studi literatur untuk setiap jenis tenaman yang tercatat di area reboisasi. Jenis tanaman dibedakan atas makanan orangutan atau bukan.

Data dari enam plot penanaman tahun 2009 dianalisis indeks ShannonWiener menggunakan persamaan:

$$
\mathrm{H}^{\prime}=-\sum_{i=1}^{R} p_{i} \ln p_{i}
$$

di mana $\mathrm{H}^{\prime}$ adalah indeks keanekaragaman Shannon-Wiener, dan $p_{i}$ adalah proporsi spesies ke- i. Analisis $\mathrm{H}^{\prime}$ dilakukan untuk menilai tingkat keberhasilan reboisasi dari struktur pohon.

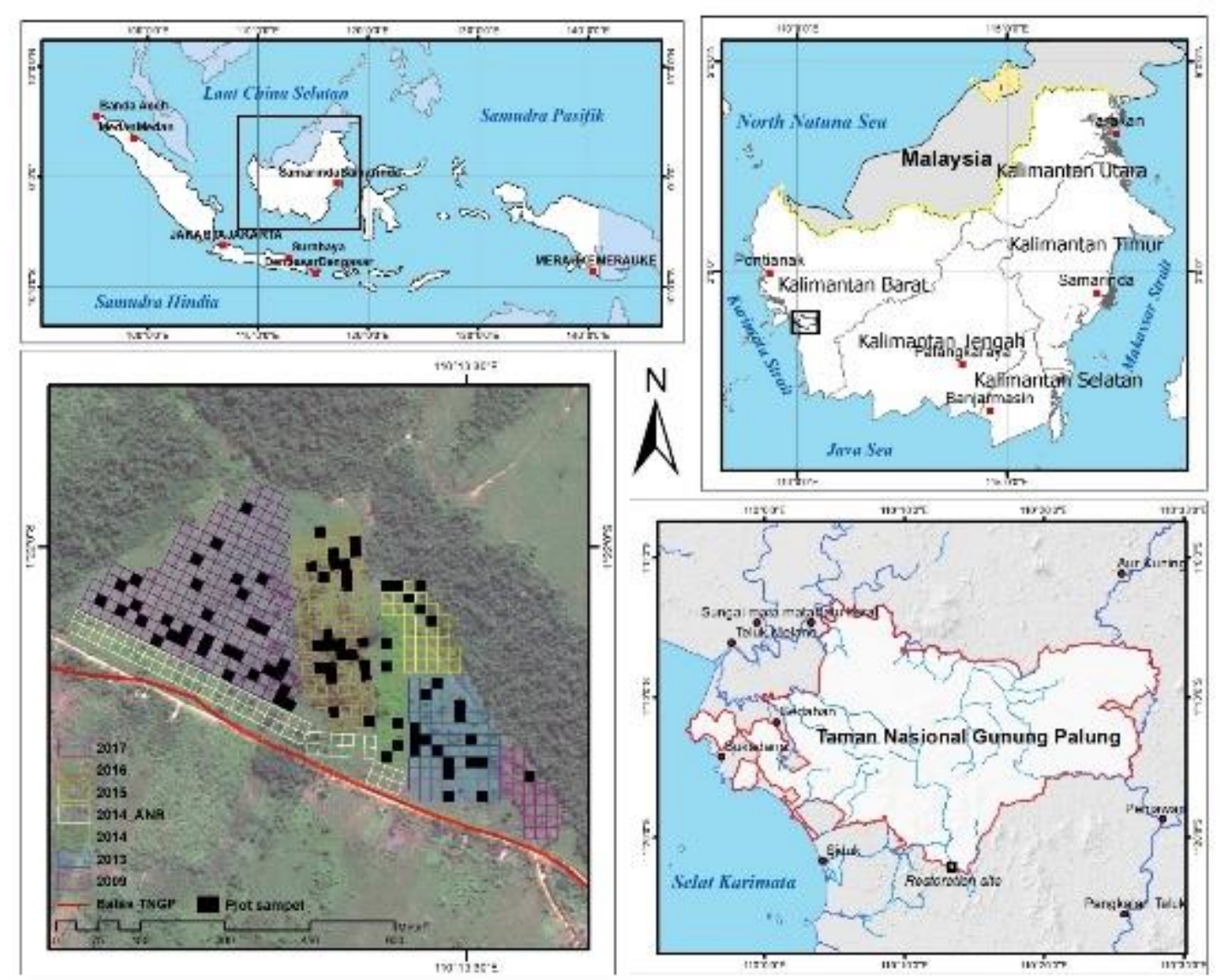

Gambar 1. Peta lokasi penelitian dan persebaran pengambilan sampel data tanaman. (The map of the research location and distribution of sampling plots)

\section{HASIL DAN PEMBAHASAN}

\section{Keberadaan Pakan Orangutan di Lokasi Reboisasi}

Orangutan merupakan frugivora atau pemakan buah ${ }^{17}$. Berbeda dengan kera di Afrika seperti gorilla yang merupakan folivora atau pemakan daun karena keterbatasan buah-buahan di hutan Afrika ${ }^{22}$. Orangutan di Borneo lebih memilih memakan buah-buahan ketika tersedia atau ketika musim buah. 
Jika tidak musim buah, mereka menghabiskan waktu untuk makan vegetasi (daun) dan kulit kayu (floem). Pola makan ini berbeda dengan orangutan Sumatra, yang lebih menghabiskan waktu untuk makan buah ara (Ficus) dan serangga. Perbedaan pola makan tersebut disebabkan oleh perbedaan distribusi pohon buah yang ada di habitat orangutan. Hutan tropis di Borneo memiliki lebih banyak biodiversitas yang membuat diet orangutan di Kalimantan lebih berserat.

Hasil monitoring pengumpulan data yang telah dilakukan, di lokasi reboisasi ASRI teridentifikasi 65 spesies pohon dari 25 suku (tabel 1). Spesies dari suku Dipterocarpaceae memiliki presentase $14 \%$ dari total spesies yang ditanam. Suku Dipterocarpaceae merupakan salah satu pohon yang menjadi sumber pakan orangutan di TN Gunung Palung. Jenisjenis pohon Dipterocarpaceae ini merupakan salah satu pakan utama orangutan ${ }^{23,24}$. Jenis pohon lainnya yang merupakan pakan orangutan adalah dari suku Moraceae dan suku Myrtaceae. Suku Myrtaceae di area reboisasi merupakan pohon jenis jambu-jambuan. Hasil analisis secara keseluruhan didapatkan komposisi spesies pohon di area reboisasi yang merupakan pakan orangutan sebesar $85 \%$. Sisanya adalah spesies asli Borneo bukan pakan orangutan, seperti pohon rengas, gaharu, sungkai, dan kayu batu.

Reboisasi di kawasan lindung mewajibkan menanam pohon sesuai spesies asli di hutan yang akan di restorasi. Kawasan TN Gunung Palung merupakan salah satu hutan yang didominasi oleh suku Dipterocarpaceae terbesar di dunia yang menjadi habitat orangutan. Proses reboisasi yang dilakukan mengharuskan komposisi dominan jenis tanaman dari suku Dipterocarpaceae. Tidak diperbolehkan menanam pisang di TN Gunung Palung, walau identik dengan makanan orangutan.

Persentasi jenis pakan orangutan yang tinggi di area reboisasi ASRI dipengaruhi oleh dua hal. Pertama, sumber bibit berasal dari hutan disekitar lokasi reboisasi. Sehingga lokasi reboisasi dapat mencerminkan kondisi hutan semua. Kedua, bibit pohon yang ditanam berasal dari masyarakat sebagai skema insentif pembayaran biaya berobat menggunakan bibit ${ }^{25}$. Sebagian besar jenis bibit yang disemaikan oleh masyarakat dari jenis buah-buahan, seperti Artocarpus, Mangifera indica, dan Parkia. Insentif pembayaran biaya berobat menggnakan bibit merupakan bagian dari pendekatan kesehatan planetari dalam program konservasi hutan.

\section{Pembahasan: Pakan Orangutan dan Reboisasi}

Salah satu tujuan reboisasi yang dilakukan oleh ASRI adalah untuk konservasi orangutan. Penambahan kelimpahan pakan orangutan di hutan termasuk tujuan jangka Panjang dari konservasi orangutan. Terdapat hubungan antara ketersediaan pakan dan kepadatan orangutan ${ }^{26}$. Hutan dengan kelimpahan spesies menghasilkan buah yang tinggi memiliki kepadatan orangutan dua kali lipat dibanding dengan hutan dengan kelimpahan yang 
rendah. Hutan yang memiliki kelimpahan spesies pohon buah memberikan nutrisi lebih banyak, orangutan tidak perlu membuat berkeliling jauh mencari makanan. Implikasinya daya jelajah orangutan yang lebih kecil yang membuah habitat mampu menampung lebih banyak populasi orangutan. Sebaliknya hutan dengan kelimpahan hutan yang sedikit akan membuat populasi hutan lebih sedikit.

Diet orangutan di TN Gunung Palung tergantung pada musim produksi buah 17. Saat musim buat, 100\% makanan orangutan adalah buah. Kalori yang diperoleh orangutan ketika musim buah mencapai $7.000-8.500$ kalori perhari. Berbeda saat bukan musim buah, proporsi makanan orangutan adalah $37 \%$ kulit kayu, $25 \%$ daun, $21 \%$ buah, $10 \%$ saripati pohon, dan $7 \%$ serangga. Praktek tebang pilih yang dilakukan oleh penebang liar di TN Gunung Palung dapat mempengaruhi ketersediaan buah di hutan. Hal ini karena dapat mengganggu proses pembuahan dan kelimpahan spesies di hutan.
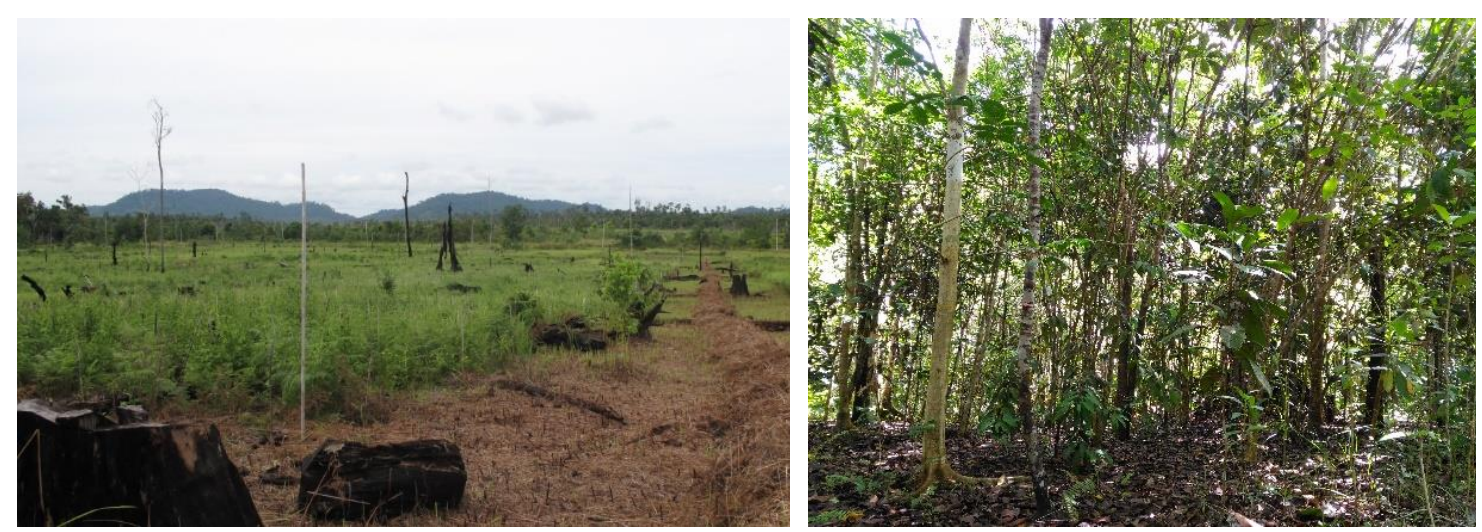

Gambar 2. Kondisi hutan yang rusak yang didominasi oleh alang-alang sebelum dilakukan reboisasi tahun 2009 (kiri) dan setelah 10 tahun program reboisasi dilakukan pada tahun 2019 (kanan). (Damaged forest conditions dominated by Imperata before restoration in 2009 (left) and after 10 years the restoration program in 2019 (right)).

Tabel 1. Daftar suku dan spesies pohon hasil monitoring di lokasi reboisasi ASRI (List of family and species from monitoring in ASRI's restoration site).

\begin{tabular}{|c|c|c|c|c|c|c|}
\hline \multirow[t]{2}{*}{ No } & \multirow[t]{2}{*}{ Suku } & & \multirow[t]{2}{*}{ Nama Latin } & \multirow[t]{2}{*}{ Nama lokal } & \multicolumn{2}{|c|}{$\begin{array}{c}\text { Makanan } \\
\text { orangutan }\end{array}$} \\
\hline & & & & & $\mathbf{Y a}$ & Bukan \\
\hline \multirow[t]{3}{*}{1} & Anacardiaceae & 1 & Dracontomelon costatum & Sengkuang & $\sqrt{ }$ & \\
\hline & & 2 & Gluta renghas $\mathrm{L}$. & Rengas & & $\sqrt{ }$ \\
\hline & & 3 & $\begin{array}{l}\text { Mangifera indica L. / Mangifera } \\
\text { spp. }\end{array}$ & Mangga & $\sqrt{ }$ & \\
\hline
\end{tabular}


JURNAL TENGKAWANG (2020)

Vol. 10 (1): 11 - 23

\begin{tabular}{|c|c|c|c|c|c|c|}
\hline \multirow[t]{2}{*}{ No } & \multirow[t]{2}{*}{ Suku } & \multirow{2}{*}{\multicolumn{2}{|c|}{ Nama Latin }} & \multirow[t]{2}{*}{ Nama lokal } & \multicolumn{2}{|c|}{$\begin{array}{c}\text { Makanan } \\
\text { orangutan }\end{array}$} \\
\hline & & & & & Ya & Bukan \\
\hline & & 4 & Pentaspadon motleyi Hook.f & Pelanjau/Kelanjau & $\sqrt{ }$ & \\
\hline 2 & Annonaceae & 5 & Annona muricata $\mathrm{L}$. & Sirsak & $\sqrt{ }$ & \\
\hline 3 & Apocynaceae & 6 & Alstonia sp. & Pulai & $\sqrt{ }$ & \\
\hline \multirow[t]{2}{*}{4} & Burceraceae & 7 & Dacryodes rostrata H.J.L. & Kayu Batu & & $\sqrt{ }$ \\
\hline & & 8 & Santiria tomentosa Blume & Kubing & $\sqrt{ }$ & \\
\hline 5 & Clusiaceae & 9 & $\begin{array}{l}\text { Calophyllum soulattri Burman f., } \\
\text { Fl. }\end{array}$ & Bintangur & & $\sqrt{ }$ \\
\hline 6 & Combretaceae & 10 & Terminalia catappa $\mathrm{L}$. & Ketapang & & $\sqrt{ }$ \\
\hline 7 & Dioscoreaceae & 11 & Dioscorea hispida Dennust & Keribang & $\sqrt{ }$ & \\
\hline \multirow[t]{9}{*}{8} & Dipterocarpaceae & 12 & Shorea stenoptera Burck & Tengkawang & $\sqrt{ }$ & \\
\hline & & 13 & Shorea sp. & Meranti & $\sqrt{ }$ & \\
\hline & & 14 & Shorea sp. & Meranti (rg) & $\sqrt{ }$ & \\
\hline & & 15 & Shorea sp. & Meranti (S) & $\sqrt{ }$ & \\
\hline & & 16 & Shorea sp. & Meranti merah & $\sqrt{ }$ & \\
\hline & & 17 & Shorea sp. & Meranti putih & $\sqrt{ }$ & \\
\hline & & 18 & Shorea palembanica Miq. & Majau & $\sqrt{ }$ & \\
\hline & & 19 & Shorea sp. & Belabak & $\sqrt{ }$ & \\
\hline & & 20 & Shorea sp. & Belabuk & $\sqrt{ }$ & \\
\hline \multirow[t]{3}{*}{9} & Euphorbiaceae & 21 & Macaranga sp. & Mahang & $\sqrt{ }$ & \\
\hline & & 22 & $\begin{array}{l}\text { Mallotus macrostachyus } \\
\text { (Miquel) Muell. Arg. }\end{array}$ & Balik Angin & & $\sqrt{ }$ \\
\hline & & 23 & Elasteriospermum tapos Miq. & Kelampai & $\sqrt{ }$ & \\
\hline \multirow[t]{3}{*}{10} & Fabaceae & 24 & Parkia sp. & Petai & $\sqrt{ }$ & \\
\hline & & 25 & Parkia speciosa Hassk & Petai Hutan & $\sqrt{ }$ & \\
\hline & & 26 & $\begin{array}{l}\text { Archidendron jiringa }(\text { Jack }) \\
\text { I.C.Nielsen }\end{array}$ & Jengkol & $\sqrt{ }$ & \\
\hline 11 & Gnetaceae & 27 & Gnetum gnemon L. & Melinjo & $\sqrt{ }$ & \\
\hline 12 & Icacinaceae & 28 & $\begin{array}{l}\text { Cantleya corniculata (Beccari) } \\
\text { Howard. }\end{array}$ & $\begin{array}{l}\text { Bedaru/lengkeng } \\
\text { hutan }\end{array}$ & $\sqrt{ }$ & \\
\hline 13 & Irvingiaceae & 29 & $\begin{array}{l}\text { Irvingia malayana Oliv ex. } \\
\text { A.Benn }\end{array}$ & $\begin{array}{l}\text { Paoh Kijang/Pauh } \\
\text { Kijang }\end{array}$ & $\sqrt{ }$ & \\
\hline 14 & Lamiaceae & 30 & Vitex pubescens Vahl. & Laban & $\sqrt{ }$ & \\
\hline \multirow[t]{2}{*}{15} & Lauraceae & 31 & Eusideroxylon zwageri T. \& B. & Ulin/Belian & $\sqrt{ }$ & \\
\hline & & 32 & Litsea sp. & Medang & $\sqrt{ }$ & \\
\hline 16 & Leeaceae & 33 & Leea indica (Burm.f.) Merr. & Mamali & $\sqrt{ }$ & $\sqrt{ }$ \\
\hline 17 & Lythraceae & 34 & Duabanga moluccana Blume & Kalamjajai & & $\sqrt{ }$ \\
\hline \multirow[t]{3}{*}{18} & Malvaceae & 35 & Durio zibethinus Murr. & Durian & $\sqrt{ }$ & \\
\hline & & 36 & Durio carinatus Mast. & Pekawai Burung & $\sqrt{ }$ & \\
\hline & & 37 & Scaphium macropodum L. & Semangkok & $\sqrt{ }$ & \\
\hline 19 & Meliaceae & 38 & $\begin{array}{l}\text { Lansium parasiticum (Osbeck) } \\
\text { Sahni \& Bennet }\end{array}$ & Langsat & $\sqrt{ }$ & \\
\hline
\end{tabular}


JURNAL TENGKAWANG (2020)

Vol. 10 (1): 11 - 23

\begin{tabular}{|c|c|c|c|c|c|c|}
\hline \multirow[t]{2}{*}{ No } & \multirow[t]{2}{*}{ Suku } & \multirow{2}{*}{\multicolumn{2}{|c|}{ Nama Latin }} & \multirow[t]{2}{*}{ Nama lokal } & \multicolumn{2}{|c|}{$\begin{array}{c}\text { Makanan } \\
\text { orangutan }\end{array}$} \\
\hline & & & & & Ya & Bukan \\
\hline & & 39 & $\begin{array}{l}\text { Swietenia macrophylla } \\
\text { (mahagoni) }\end{array}$ & Mahoni & & $\sqrt{ }$ \\
\hline \multirow[t]{6}{*}{20} & Moraceae & 40 & $\begin{array}{l}\text { Artocarpus integer (Thund.) } \\
\text { Merr. }\end{array}$ & Cempedak & $\sqrt{ }$ & \\
\hline & & 41 & Ficus variegata $\mathrm{Bl}$. & Kondang & $\sqrt{ }$ & \\
\hline & & 42 & Artocarpus sp. & Mentawak & $\sqrt{ }$ & \\
\hline & & 43 & Artocarpus sp. & Mentawak merah & $\sqrt{ }$ & \\
\hline & & 44 & Artocarpus sp. & Mentawak pintau & $\sqrt{ }$ & \\
\hline & & 45 & Artocarpus integra & Nangka & $\sqrt{ }$ & \\
\hline \multirow[t]{7}{*}{21} & Myrtaceae & 46 & Syzigium sp. & Ubah & $\sqrt{ }$ & \\
\hline & & 47 & Syzigium sp. & Ubah Jambu & $\sqrt{ }$ & \\
\hline & & 48 & Syzigium sp. & Ubah merah & $\sqrt{ }$ & \\
\hline & & 49 & Syzigium sp. & Ubah putih & $\sqrt{ }$ & \\
\hline & & 50 & Syzygium sp. & Jambu & $\sqrt{ }$ & \\
\hline & & 51 & Syzygium aqueum (Burm.f.) Alst. & Jambu air & $\sqrt{ }$ & \\
\hline & & 52 & Psidium guajava $\mathrm{L}$. & Jambu biji & $\sqrt{ }$ & \\
\hline 22 & Phyllanthaceae & 53 & Baccaurea motleyana Müll.Arg. & Rambai & $\sqrt{ }$ & \\
\hline \multirow[t]{2}{*}{21} & Rubiaceae & 54 & Uncaria sp. & Kelait & $\sqrt{ }$ & \\
\hline & & 55 & Morinda citrifolia $\mathrm{L}$. & Mengkudu & $\sqrt{ }$ & \\
\hline 23 & Rutaceae & 56 & Citrus sp. & Jeruk & $\sqrt{ }$ & \\
\hline 24 & Salicaceae & 57 & Flacourtia rukam Zoll. \& Mor. & Rukam & $\sqrt{ }$ & \\
\hline \multirow[t]{3}{*}{25} & Sapindaceae & 58 & Nephelium sp. & Rambutan & $\sqrt{ }$ & \\
\hline & & 59 & Nephelium sp. & Rangkung & $\sqrt{ }$ & \\
\hline & & 60 & Dimocarpus longan Lour. & Lengkeng & $\sqrt{ }$ & \\
\hline \multirow[t]{2}{*}{26} & Sapotaceae & 61 & Palaquium leiocarpum Boerl. & Jongkang & $\sqrt{ }$ & \\
\hline & & 62 & Palaquium Blanco & Nyatoh & $\sqrt{ }$ & \\
\hline 27 & Thymelaeaceae & 63 & Aquilaria malaccensis Lamk. & Gaharu & & $\sqrt{ }$ \\
\hline 28 & Verbenaceae & 64 & Peronema canescens Jack & Sungkai & & $\sqrt{ }$ \\
\hline 29 & Asteraceae & 65 & Vernonia arborea Ham & Tetepungan & $\sqrt{ }$ & \\
\hline
\end{tabular}

Tabel 2. Daftar suku dan spesies pohon hasil monitoring pada plot penanaman tahun 2009 dengan DBH $\geq \mathbf{5} \mathbf{~ c m}$ di lokasi reboisasi ASRI (List of family and species from monitoring on 2009's plots with $D B H>5 \mathrm{~cm}$ in ASRI's restoration site).

\begin{tabular}{lccllcc}
\hline No & \multirow{2}{*}{ Family } & & \multicolumn{1}{c}{ Nama Latin } & Nama Lokal & K & (\%) \\
\hline 1 & Anacardiaceae & 1 & Gluta renghas L. & Rengas & 1 & 0,91 \\
\hline & & 2 & Anacardium occidentale L. & Jambu mete & 1 & 0,91 \\
\hline & & 3 & Mangifera indica L. & Mangga & 10 & 9,85 \\
\hline 2 & Apocynaceae & 4 & Alstonia scholaris L. R. Br. & Pulai & 1 & 0,91 \\
\hline 3 & Calophyllaceae & 5 & Calophyllum hosei Ridley & Bentangor & 1 & 0,91 \\
\hline
\end{tabular}


JURNAL TENGKAWANG (2020)

Vol. 10 (1): 11 - 23

\begin{tabular}{|c|c|c|c|c|c|c|}
\hline 4 & Datiscaceae & 6 & Octomeles sumatrana Miq. & Benuang & 2 & 1,93 \\
\hline \multirow[t]{3}{*}{5} & Dipterocarpaceae & 7 & Shorea leprosula Miq. & Meranti Merah & 1 & 0,91 \\
\hline & & 8 & Shorea lepidota (Korth.) Blume. & $\begin{array}{l}\text { Tengkawang } \\
\text { gunung }\end{array}$ & 2 & 1,93 \\
\hline & & 9 & Shorea scaberrima Burck. & Tengkawang batu & 1 & 0,91 \\
\hline \multirow[t]{2}{*}{6} & Euphorbiaceae & 10 & $\begin{array}{l}\text { Macaranga mauritiana Bojer ex } \\
\text { Baill. }\end{array}$ & Mahang & 1 & 0,91 \\
\hline & & 11 & $\begin{array}{l}\text { Macaranga tribola (Thunb.) } \\
\text { Müll.Arg. }\end{array}$ & Makaranga & 4 & 3,86 \\
\hline \multirow[t]{3}{*}{7} & Fabaceae & 12 & Parkia speciosa & Petai & 1 & 0,91 \\
\hline & & 13 & Intsia bijuga (Colebr.) O.K & Merbau & 4 & 3,86 \\
\hline & & 14 & $\begin{array}{l}\text { Archidendron pauciflorum } \\
\text { (Benth.) I.C.Nielsen }\end{array}$ & Jengkol & 1 & 0,91 \\
\hline \multirow[t]{2}{*}{8} & Lauraceae & 15 & Litsea nidularis Gamble & Medang keladi & 1 & 0,91 \\
\hline & & 16 & Litsea turfosa Kosterm. & Medang mali & 1 & 0,91 \\
\hline \multirow[t]{3}{*}{9} & Myrtaceae & 17 & $\begin{array}{l}\text { Syzygium lineatum (DC.) Merrill } \\
\text { \& Perry }\end{array}$ & Ubah Merah & 15 & 14,73 \\
\hline & & 18 & $\begin{array}{l}\text { Syzygium zollingerianum (Miq.) } \\
\text { Ams. }\end{array}$ & Ubah Jambu & 6 & 5,89 \\
\hline & & 19 & Syzygium sp. & Ubah Putih & 4 & 3,86 \\
\hline 10 & Myristicaceae & 20 & Knema perconacea Sinch. & Kumpang & 1 & 0,91 \\
\hline \multirow[t]{3}{*}{11} & Moraceae & 21 & Artocarpus heterophyllus Lamk. & Nangka & 8 & 7,82 \\
\hline & & 22 & Ficus variegata $\mathrm{Bl}$ & Kondang & 1 & 0,91 \\
\hline & & 23 & $\begin{array}{l}\text { Artocarpus integer (Thunb.) } \\
\text { Merr. }\end{array}$ & Cempedak & 5 & 4,87 \\
\hline 12 & Phyllanthaceae & 24 & Baccaurea motleyana Müll.Arg. & Rambai & 5 & 4,87 \\
\hline 13 & Salicaceae & 25 & Flacourtia rukam & Rukam & 1 & 0,91 \\
\hline 14 & Sapindaceae & 26 & Nephelium lappaceum $\mathrm{L}$. & Rambutan & 17 & 16,76 \\
\hline 15 & Sapotaceae & 27 & Palaquium coclearifoium Boerl. & Nyatoh & 4 & 3,86 \\
\hline \multirow[t]{2}{*}{16} & Styracaceae & 28 & Styrax benzoine Dryand & Kemenjen & 3 & 2,94 \\
\hline & & & & Total & 103 & 100 \\
\hline
\end{tabular}

Ketersediaan pakan orangutan saat tidak musim buah membuat orangutan menjelajah lebih jauh untuk mendapatkankan makanan. Karena menipisnya kelimpahan pakan di hutan, orangutan mulai memperluas jelajah mencari makan ke daerah pemukiman atau kebun masyarakat. Hal tersebut menyebabkan konflik antara orangutan dan masyarakat.

Keberadaan area reboisasi membantu mencegah konflik ini karena orangutan dapat mencari makanan di area reboisasi.
Pada area reboisasi di ASRI, terdapat keberadaan orangutan yang ditandai dengan ditemukannya sarang orangutan. Keberadaan satwa liar lainnya juga meningkat dengan terbentuknya kanopi hutan ${ }^{28}$. Jejak-jejak babi liar (Sus barbatus) sering tampak pada lahan yang telah menghasilkan buah.

\section{Pembahasan: Indeks Shannon-Wiener}

Ketersediaan spesies pakan orangutan tidak membuat program reboisasi berhasil. Terbentuknya kanopi hutan, komposisi dan 
struktur pohon, dan keberadaan satwa liar menjadi parameter lain yang harus diperhatikan. Analisis bio-monitoring diperlukan untuk menilai keberhasilan program reboisasi. Hasil analisis indeks Shannon-Wiener (H') pada lahan tahun 2009, didapatkan nilai $H^{\prime}=2,789$. Hasil menunjukkan bahwa hutan sekunder hasil reboisasi berada dalam kondisi menengah atau stabil (kondisi stabil jika $1<\mathrm{H}^{\prime}<3$ ). Kondisi ini menunjukkan sukses dalam proses reboisasi. Indeks Shannon-Wiener untuk hutan sekunder yang tua berada pada rentang 3,40 dan untuk hutan primer adalah $4,17^{29}$.

Keberagaman spesies di hutan hasil reboisasi menunjukkan hasil yang baik dan stabil. Kepadatan spesies dengan DBH > 5 cm mencapai 430 pohon per hektar. Terdapat anakan alami dari spesies laban (Vitex pinnata) yang disebarkan oleh burung. Selain spesies pohon, peningkatan kehadiran satwa liar perlu ditingkatkan melalui pengurangan aktivitas manusia di lahan reboisasi. Upaya ini dapat membuat kehadiran jumlah spesies burung meningkat hingga tujuh kali lipat ${ }^{28}$.

Fungsi keberadaan reboisasi selain untuk restorasi hutan dan habitat bagi satwa liar, juga berguna untuk preservasi dan konservasi hutan disekitar lokasi reboisasi. Adanya program reboisasi yang dilakukan oleh ASRI mampu melindungi hutan hingga seluas 1.600 hektar. Aktivitas reboisasi di sekitar TN Gunung Palung membuat penebang liar takut untuk menebang. Hal ini sejalan bahwa perlindungan habitat orangutan merupakan upaya paling efisien untuk melindungi orangutan ${ }^{30}$. Persepsi masyarakat juga telah berubah mendukup upaya konservasi dengan adanya program reboisasi ${ }^{31}$.

\section{KESIMPULAN}

Terdapat 65 spesies pohon dari 25 suhu pada lokasi reboisasi ASRI di Kawasan TN Gunung Palung. Sebanyak 85\% dari spesies tersebut adalah pakan orangutan. Pohon dari suku Dipterocarpaceae memiliki presentase $14 \%$ dari total spesies yang ditanam. Selain sebagai pakan orangutan, keberadaan area reboisasi membantu mencegah konflik ini karena orangutan dapat mencari makanan di area reboisasi. Analisis indeks ShannonWiener (H') pada lahan tahun 2009, didapatkan nilai $H^{\prime}=2,789$. Hasil ini menunjukkan hutan hasil reboisasi berada dalam kondisi menengah atau stabil. Efek peningkatan biodiversitas ditandai dengan sarang-sarang orangutan ditemukan di lokasi reboisasi dan keberadaan satwa liar telah meningkat.

\section{UCAPAN TERIMA KASIH/ ACKNOWLEDGEMENT}

Ucapan terima kasih diberikan kepada seluruh donor yang telah mendukung program reboisasi yang dilakukan ASRI di kawasan TN Gunung Palung. Serupa kepada seluruh masyarakat di Desa Laman Satong untuk dukungan dalam mendukung upaya konservasi hutan untuk perlidungan habitat orangutan.

\section{DAFTAR PUSTAKA}

Alroy, J. (2017). Effects of habitat disturbance on tropical forest biodiversity. Proceedings of the National Academy of Sciences of the United States of America, 114(23), 6056-6061. 
https://doi.org/10.1073/pnas.161185 5114

Ancrenaz, M., Gumal, M., Marshall, A. J., Meijaard, E., Wich, S. A., \& Husson, S. (2016). Pongo pygmaeus (errata version published in 2018). The IUCN Red List of Threatened Species 2016: e.T17975A123809220.

https://doi.org/10.2305/IUCN.UK.2 016-1.RLTS.T17975A17966347.en

Baccini, A., Goetz, S. J., Walker, W. S., Laporte, N. T., Sun, M., SullaMenashe, D., Hackler, J., Beck, P. S. A., Dubayah, R., Friedl, M. A., Samanta, S., \& Houghton, R. A. (2012). Estimated carbon dioxide emissions from tropical deforestation improved by carbon-density maps. Nature Climate Change, 2(3), 182185.

https://doi.org/10.1038/nclimate135 4

Brearley, F. Q., Prajadinata, S., Kidd, P. S., Proctor, J., \& Suriantata. (2004). Structure and floristics of an old secondary rain forest in Central Kalimantan, Indonesia, and a comparison with adjacent primary forest. Forest Ecology and Management, 195(3), 385-397. https://doi.org/10.1016/j.foreco.2004 .02 .048

Cipta, H. (2019). Penyelamatan Orangutan Bernama Riam dan Habitatnya yang Rusak di Ketapang. https://regional.kompas.com/read/20 19/05/10/16001471/penyelamatanorangutan-bernama-riam-danhabitatnya-yang-rusak-di-ketapang

Curran, L. M., Trigg, S. N., Mcdonald, A K., \& Astiani, D. (2004). Lowland Forest Loss in Protected Areas. Terra, 303(February), 1000-1003. https://doi.org/10.1126/science.1091 714

Elliott, S. D., Blakesley, D., \& Hardwick, K. (2013). Restoring tropical forests: a practical guide. Kew Publishing, Royal Botanic Gardens, Kew.

Fawzi, N. I., Indrayani, A. M., \& DeKay, K. (2019). Forest Change Monitoring and Environmental Impact in Gunung Palung National Park, West Kalimantan, Indonesia. Jurnal Ilmu Lingkungan, 17(2), 197204.

https://doi.org/10.14710/jil.17.2.197 $-204$

Gaveau, D. L. A. A., Sheil, D., Husnayaen, Salim, M. A., Arjasakusuma, S., Ancrenaz, M., Pacheco, P., \& Meijaard, E. (2016). Rapid conversions and avoided deforestation: Examining four decades of industrial plantation expansion in Borneo. Scientific Reports, $6(1), \quad 32017$. https://doi.org/10.1038/srep32017

Gaveau, D. L. A., Locatelli, B., Salim, M. A., Yaen, H., Pacheco, P., \& Sheil, D. (2019). Rise and fall of forest loss and industrial plantations in Borneo (2000-2017). Conservation Letters, 12(3), 1-8. https://doi.org/10.1111/conl.12622

Giam, X. (2017). Global biodiversity loss from tropical deforestation. Proceedings of the National Academy of Sciences of the United States of America, 114(23), 57755777.

https://doi.org/10.1073/pnas.170626 4114

Helms, J. A., Woerner, C. R., Fawzi, N. I., MacDonald, A., Juliansyah, Pohnan, E., \& Webb, K. (2018). Rapid Response of Bird Communities to Small-Scale Reforestation in 
Indonesian Borneo. Tropical Conservation Science, 11, 1-8. https://doi.org/10.1177/1940082918 769460

Holl, K. D. (2017). Restoring tropical forests from the bottom up. Science, 355(6324), 455-456. https://doi.org/10.1126/science.aam 5432

Johnson, A. E., Knott, C. D., Pamungkas, B., Pasaribu, M., \& Marshall, A. J. (2005). A survey of the orangutan (Pongo pygmaeus wurmbii) population in and around Gunung Palung National Park, West Kalimantan, Indonesia based on nest counts. Biological Conservation, 121(4), $\quad$ 495-507. https://doi.org/10.1016/J.BIOCON.2 004.06.002

Knott, C. D. (1999a). Gunung Palung orangutan food list. In C. Yeager (Ed.), Orangutan Action Plan (pp. 21-26). World Wildlife Fund.

Knott, C. D. (1999b). Orangutan Behavior and Ecology. In P. Dolhinow \& A. Fuentes (Eds.), The Nonhuman Primates (pp. 50-57). Mayfield Press.

Lawrence, D., \& Vandecar, K. (2015). Effects of tropical deforestation on climate and agriculture. Nature Climate Change, 5(1), 27-36. https://doi.org/10.1038/nclimate243 0

Meijaard, E., Wich, S., Ancrenaz, M., \& Marshall, A. J. (2012). Not by science alone: Why orangutan conservationists must think outside the box. Annals of the New York Academy of Sciences, 1249(1), 2944. https://doi.org/10.1111/j.17496632.2011.06288.x
Newmark, W. D., Jenkins, C. N., Pimm, S. L., McNeally, P. B., \& Halley, J. M. (2017). Targeted habitat restoration can reduce extinction rates in fragmented forests. Proceedings of the National Academy of Sciences of the United States of America, 114(36), 9635-9640. https://doi.org/10.1073/pnas.170583 4114

Ode, M. D. L. (2012). Etnis Cina Indonesia dalam Politik: Politik Etnis Cina dan Singkawang di era Reformasi 19982008. Yayasan Pustaka Obor Indonesia.

https://books.google.co.id/books?id $=$ S6fUCwAAQBAJ

Pohnan, E., Ompusunggu, H., \& Webb, C. (2015). Does tree planting change minds? Assessing the use of community participation in reforestation to address illegal logging in West Kalimantan. Tropical Conservation Science, 8(1), 45-57.

https://doi.org/10.1177/1940082915 00800107

Rahman, D. A. (2010). Karakteristik Habitat dan Preferensi Pohon Sarang Orangutan (Pongo Pygmaeus Wurmbii) di Taman Nasional Tanjung Puting (Studi Kasus Camp Leakey). Jurnal Primatologi Indonesia, 7(2), 37-50.

Sandor, M. E., \& Chazdon, R. L. (2014). Remnant Trees Affect Species Composition but Not Structure of Tropical Second-Growth Forest. PLoS ONE, 9(1), e83284. https://doi.org/10.1371/journal.pone. 0083284

Stanturf, J. A., Palik, B. J., \& Dumroese, R. K. (2014). Contemporary forest restoration: A review emphasizing function. Forest Ecology and 
Management, 331, 292-323. https://doi.org/10.1016/J.FORECO. 2014.07.029

Taylor, A. B. (2008). The functional significance of variation in jaw form in orangutans. In and C. P. van S. Serge A. Wich, S Suci Utami Atmoko, Tatang Mitra Setia (Ed.), Orangutans: Geographic Variation in Behavioral Ecology and Conservation (pp. 15-32). Oxford University Press. https://doi.org/10.1093/acprof:oso/9 780199213276.003.0002

Tsujino, R., Yumoto, T., Kitamura, S., Djamaluddin, I., \& Darnaedi, D. (2016). History of forest loss and degradation in Indonesia. Land Use Policy, 57, 335-347. https://doi.org/10.1016/j.landusepol. 2016.05.034

van der Werf, G. R., Morton, D. C., DeFries, R. S., Olivier, J. G. J., Kasibhatla, P. S., Jackson, R. B., Collatz, G. J., \& Randerson, J. T. (2009). CO2 emissions from forest loss. Nature Geoscience, 2(11), 737738.

https://doi.org/10.1038/ngeo671

Vogel, E. R., Harrison, M. E., Zulfa, A., Bransford, T. D., Alavi, S. E., Husson, S., Morrogh-Bernard, H., Santiano, Firtsman, T., UtamiAtmoko, S. S., van Noordwijk, M. A., \& Farida, W. R. (2015). Nutritional Differences between Two Orangutan Habitats: Implications for Population Density. PLOS ONE, 10(10), e0138612. https://doi.org/10.1371/journal.pone. 0138612

Webb, K., Jennings, J., \& Minovi, D. (2018). A community-based approach integrating conservation, livelihoods, and health care in
Indonesian Borneo. The Lancet Planetary Health, 2, S26. https://doi.org/10.1016/S25425196(18)30111-6

Wilson, H. B., Meijaard, E., Venter, O., Ancrenaz, M., \& Possingham, H. P. (2014). Conservation Strategies for Orangutans: Reintroduction versus Habitat Preservation and the Benefits of Sustainably Logged Forest. PLoS ONE, 9(7), e102174. https://doi.org/10.1371/journal.pone. 0102174

Wolff, N. H., Masuda, Y. J., Meijaard, E., Wells, J. A., \& Game, E. T. (2018). Impacts of tropical deforestation on local temperature and human wellbeing perceptions. Global Environmental Change, 52, 181189.

https://doi.org/10.1016/J.GLOENV

CHA.2018.07.004 